\title{
Magnetic Resonance Imaging of Meningio-Angiomatosis
}

\author{
Ruben Kuzniecky, Denis Melanson, Yves Robitaille and André Olivier
}

\begin{abstract}
We report the case of a patient with meningio-angiomatosis, a rare disorder of the cerebral cortex often associated with Von Recklinghausen's neurofibromatosis. Previous reports have described a variety of radiological findings but in general they have been of little value in the diagnosis of this disorder. We describe the magnetic resonance image, which identified a well-defined lesion. The imaging techniques are reviewed.
\end{abstract}

RÉSUMÉ: Imagerie par resonance magnetique de l'angiomatose méningée Nous rapportons le cas d'un patient porteur d'une angiomatose méningée, une affection rare du cortex cérébral souvent associée à la neurofibromatose de Von Recklinghausen. Chez les cas déjà rapportés, on a décrit différentes observations radiologiques qui sont en général peu utiles pour le diagnostic de cette maladie. Nous décrivons l'image obtenue par résonance magnétique, image qui identifie une lésion bien définie. Nous revoyons les différentes technique d'imagerie.

Can. J. Neurol. Sci. 1988; 15:161-164

Meningio-angiomatosis is a rare lesion of the central nervous system which is classically associated with neurofibromatosis. ${ }^{1,2}$ Isolated forms of this disorder have also been reported. ${ }^{3,4}$ Histologically, the lesion is characterized by cortical meningiovascular proliferation and leptomeningeal calcifications. The appearance of meningiomatosis at angiography and computed tomography (CT) has been described, ${ }^{4}$ but the use of magnetic resonance imaging (MRI) has not been reported. For this reason, we describe one patient with such a lesion to illustrate its appearance on conventional techniques and to compare it with MRI.

\section{Case Report}

This 24-year-old man was well until 1980, when he developed partial complex seizures. There was no history of trauma, infection or surgery, and the family history was negative. The seizures were characterized by an ill defined epigastric sensation followed by voices and musical sounds lasting approximately 15 seconds. On three occasions this was followed by generalized tonic-clonic convulsions. No abnormalities were found on general physical or neurological examination. He was treated with phenytoin and remained seizure-free until 1984 when he developed recurrent seizures. A computerized tomography (CT) scan at this time showed a right temporal calcified lesion; the patient refused further investigations and was discharged home. One year later he was admitted to the Montreal Neurological Hospital for uncontrollable seizures.
Investigations Electroencephalographic studies showed intermittent theta and sharp wave activity over the right mid-temporal region. Skull films demonstrated a calcification in the right temporal fossa. CT scans, with and without contrast enhancement, revealed a well-defined calcified mass in the right temporal lobe (Figure 1). Selective right internal-external carotid arteriography was normal.

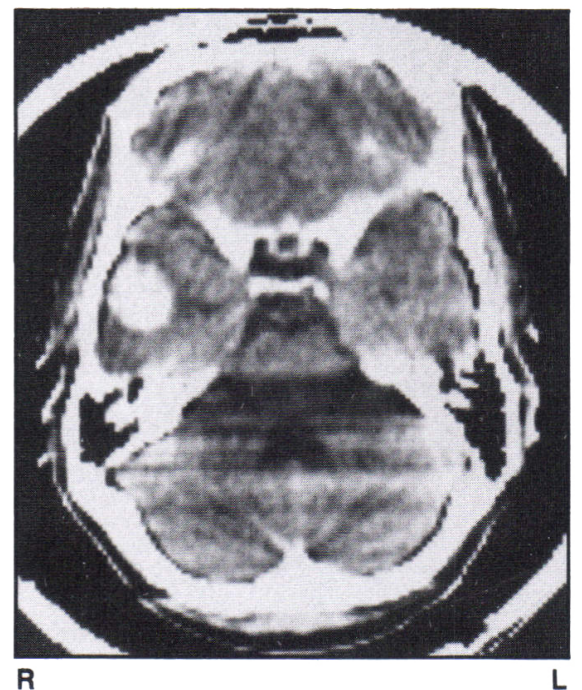

Figure I - Non-contrast computed tomography (CT) scan shows a well-demarcated hyperdense lesion in the right temporal lobe.

From the Department of Neurology and Neurosurgery, McGill University, Montreal Neurological Hospital and Institute, Montreal Received June 23, 1987. Accepted in final form January 8, 1988

Reprint requests to: Dr. Denis Melanson, Dept of Neuro-Radiology, Montreal Neurological Hospital and Institute, 3801 University St., Montreal, Quebec, Canada H3A 2B4 
Magnetic resonance imaging (MRI) was performed using a superconductive magnet (Philips Gyroscan) operating at a field strength of 0.5 Tesla. T2-weighted images were generated by spin-echo pulse sequences with an echo time (TE) of $50 \mathrm{~ms}$ and $100 \mathrm{~ms}$ and a repetition time (TR) of $1600 / 1700 \mathrm{~ms}$. On the axial plane, a well-circumscribed lesion was seen in the right mid-temporal region. The core of the lesion appeared non-homogeneous with a fine stippling within it. The rim surrounding the center of the lesion consisted of three different signals; a middle iso-intense signal enclosed by an inner and outer rim of increased intensity (Figure 2).

Operation A right fronto-temporo-parietal craniotomy was performed. There were no gross abnormalities except for some widening of the second temporal gyrus on the exposed cortex. However, palpation revealed marked induration over the mid-temporal region. Pre-excision electrocorticography revealed epileptic discharges predominantly over the first temporal gyrus anteriorly and from the second temporal gyrus rostral to the lesion.

Following electrocorticography, removal of the mass was done along the temporal gyrus through a plane superfical and ventral to the insular vessels. The resection was then directed mesially and the calcified mass was removed in toto. Subsequently, the temporal horn was opened and the anterior $2.5 \mathrm{~cm}$ of the hippocampus as well as the uncus and the amygdala were resected. Post-excision electrocorticogram revealed residual spiking from the anterior portion of the second temporal gyrus. After anterior corticectomy, no residual epileptic activity was recorded. The post-operative course was unremarkable and the patient has remained seizure-free two years following surgery.

Pathological examination Many representative sections of the lesion and of the electrocorticographically epileptic areas were submitted for examination. All sections were stained with hematoxylin-eosin, KluverBarrera, Cajal's gold chloride sublimate, and modified Bielschowsky.

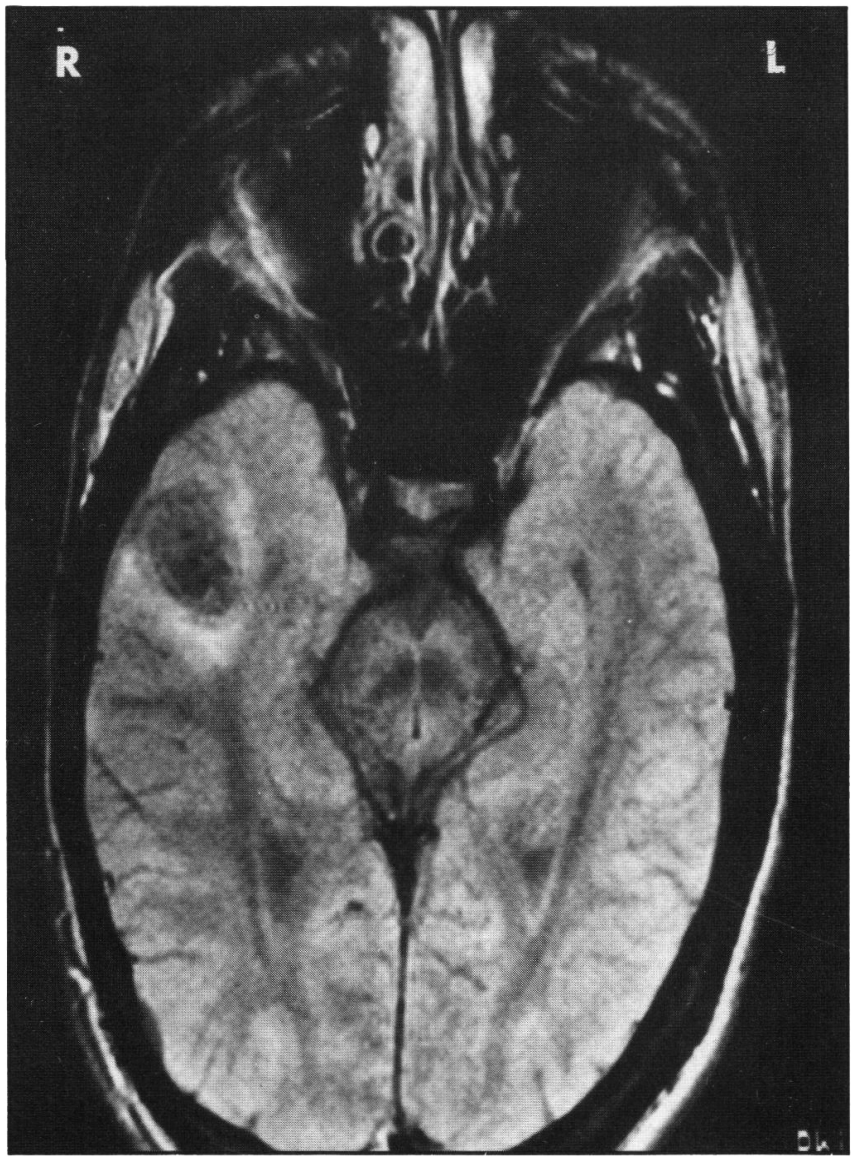

Figure $2 a-$ Magnetic resonance (MR) axial (TE $50 \mathrm{~ms}-T R 1600 \mathrm{~ms}$ ) showing a well circumscribed lesion in the right temporal lobe. Note stippling in the center and hyperintense signal on the periphery.
The resected specimen consisted of a calcified central core surrounded by a thick, firm gray-beige capsule (Figure 3 ). The core consisted of arachnoidal cells which displayed numerous whorls and psammoma bodies. The capsule consisted of cortex infiltrated by well-differentiated spindle cells mostly within the Virchow-Robin spaces of small arteries and veins, which frequently formed psammoma bodies (Figure 4). The neuropil was gliotic and itself infiltrated by arachnoidal cells and collagenous tissue overflowing Virchow-Robin spaces. Neurofibrillary tangles were present in the cytoplasm of many residual neurons within the lesion and the adjacent cortex. The lateral temporal neocortex and hippocampus uninvolved by the above described lesions, showed moderate neuronal loss and gliosis. A diagnosis of meningio-angiomatosis of the right lateral middle temporal lobe was made.

\section{DISCUSSION}

Meningio-angiomatosis is a rare disorder that involves the cerebral cortex and often the overlying leptomeninges. ${ }^{1-4}$ It is usually associated with Von Recklinghausen's neurofibromatosis. However, several cases dissociated from Von Recklinghausen's disease have been reported. ${ }^{3,4}$ The clinical features include seizures or increased intracranial pressure, but in the majority of patients, the process is asymptomatic or an incidental autopsy finding. ${ }^{4}$ The pathological features are characterized by cortical meningio-angiomatous proliferation associated with psammoma bodies and vascular calcifications. ${ }^{4,5}$ Leptomeningeal calcifications are often present. More recently, Alzheimer's neurofibrillary tangles have been reported in meningio-angio-

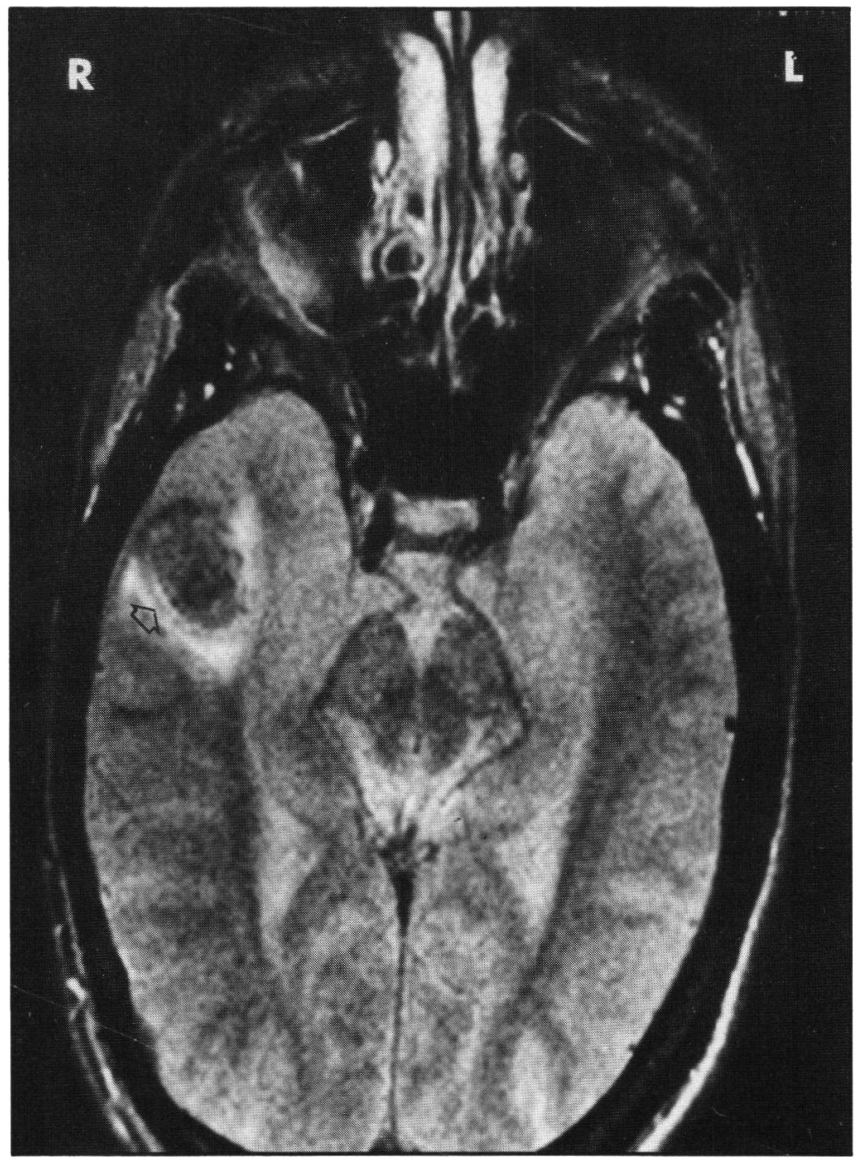

Figure $2 b$ - Axial (TE $100 \mathrm{~ms}$ - TR $1700 \mathrm{~ms}$ ); signal from the periphery increases with prolonged TE. Note that the isointense signal corresponding to the lesion's capsule is more noticeable (arrow). For more details see text. 
matosis, ${ }^{4}$ although the significance of these findings remains to be determined.

Radiologic findings in most reported cases of meningioangiomatosis have been heterogeneous (Table 1). Kasantikul and associates, ${ }^{3}$ who first reported the isolated forms of meningioangiomatosis, described two patients with seizures. CT and angiography were normal in one, whereas in the other patient, angiography revealed a cluster of abnormal vessels. Halper et $\mathrm{al}^{4}$ reported another 4 patients. Angiography revealed no abnormalities in 3; CT scan showed calcifications in 1 and was normal in the third patient. In the present case, angiography was normal and CT scan showed a non-specific calcified lesion. This

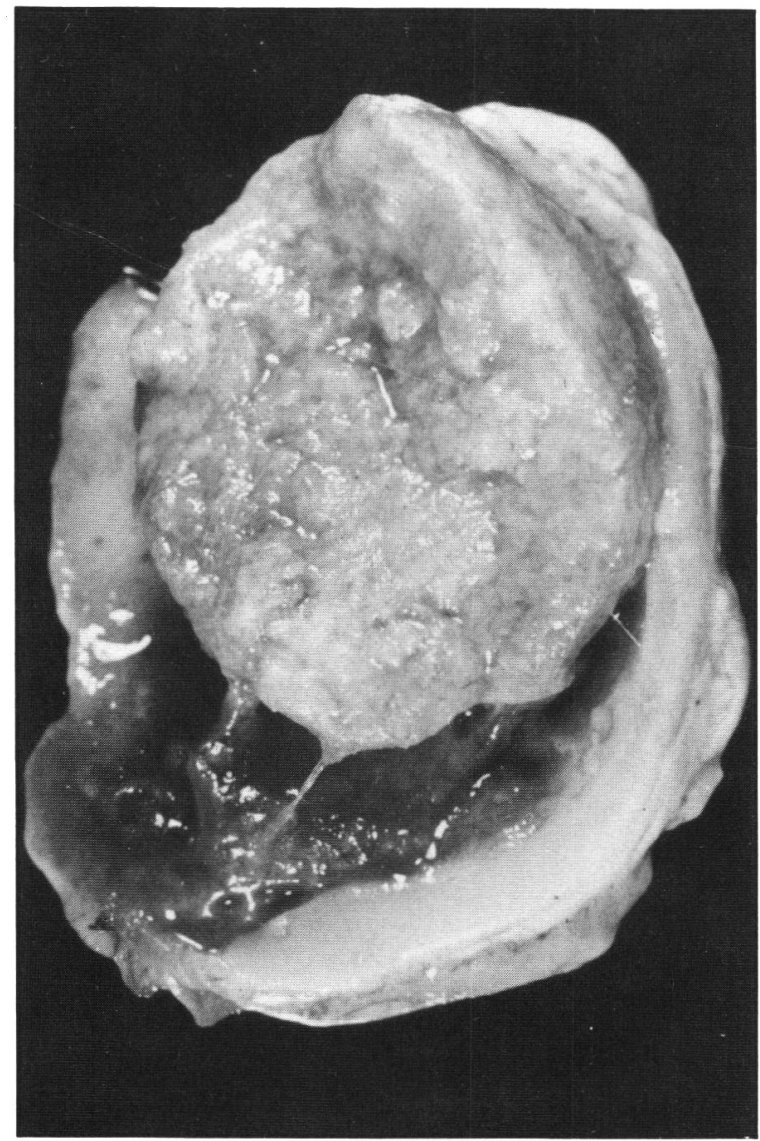

Figure 3 - Gross appearance of the specimen. Note correlation with $M R$ image, characterized by transitional meningioma-like central core surrounded by a thick capsule made of abnormal cortex. diversity of findings can be explained if one considers that the lesions may be congenital in nature, but, possibly due to degenerative changes in the vascular component of the lesion (leptomeninges), could become progressively calcified.

To our knowledge, the MRI appearance of meningio-angiomatosis has not been described previously. The MRI findings we observed revealed a well-circumscribed lesion in the right mid-temporal lobe. The center had a mottling appearance and did not change in the second echo. In contrast, the rim signal became more intense with prolongation of the TE (100 ms). A gross pathological correlation of the MRI findings (Figure 2 and Figure 3) shows the excellent anatomical concordance between the image and the lesion. Histological correlation revealed that the lesion's center resembled a calcified transitional meningioma. This may explain the fine stippling within the lesion and the lack of intensity seen with different echos. These MRI features have been observed in typical meningiomas. ${ }^{6}$ The lesion's "capsule" consisted of cortex infiltrated by collagenous tissue and arachnoidal cells and corresponded to the well-defined isointense rim seen on the periphery of the lesion. The less circumscribed outer hyperintense signal surrounding the lesion corresponded to moderate neuronal loss and gliosis of the adjacent cortex. The inner rim of increased intensity may correspond to a chemical shift.

Although we have demonstrated the ability of MRI to image meningio-angiomatosis, the specificity will remain uncertain

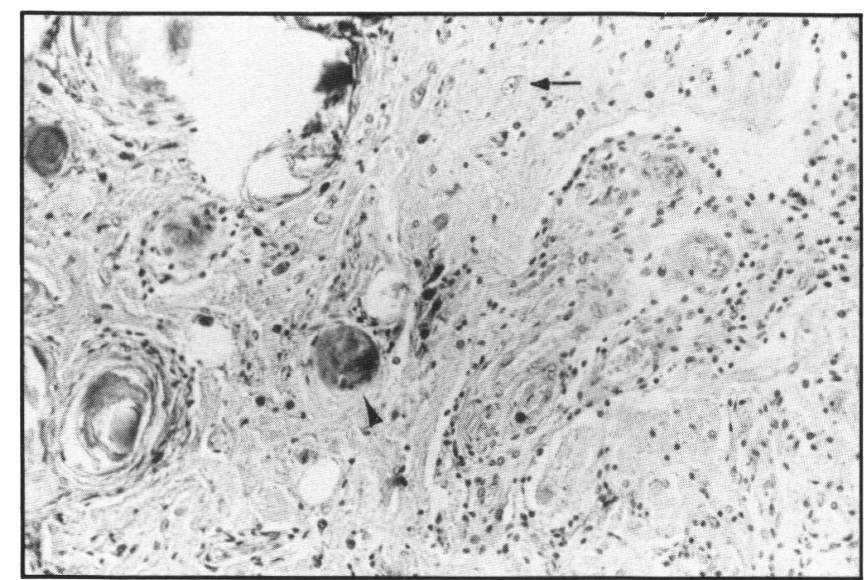

Figure 4-Microscopic section of the capsule showing cortex infiltrated by spindle cells within the perivascular spaces. Note residual neurons (arrow) and psammoma bodies (arrowhead). (Gomori-Tichrome X 200).

Table 1: Clinico-Radiological Features of Reported Cases of Meningio-Angiomatosis

\begin{tabular}{|c|c|c|c|c|c|c|}
\hline Reference No & $\begin{array}{c}\text { Age/ } \\
\text { Sex }\end{array}$ & $\begin{array}{c}\text { Clinical } \\
\text { presentation }\end{array}$ & X-Ray & Angio & CT & MRI \\
\hline 1 & $25 / \mathrm{M}$ & Autopsy finding & ND & - & 一 & 一 \\
\hline 2 & $17 / \mathrm{F}$ & Seizures & NS & NS & 一 & 一 \\
\hline 5 & $39 / \mathrm{M}$ & Autopsy finding & ND & - & - & - \\
\hline \multirow[t]{2}{*}{3} & $15 / \mathrm{M}$ & Seizures & Calcification & Abnormal vasculature & - & - \\
\hline & $23 / \mathrm{M}$ & Seizures & Normal & Normal & Normal & - \\
\hline \multirow[t]{4}{*}{4} & $26 / F$ & Seizures & NS & Normal & Normal & - \\
\hline & $30 / \mathrm{M}$ & Seizures & NS & Normal & Calcification & - \\
\hline & $10 / \mathrm{F}$ & Seizures & NS & NS & Calcification & 一 \\
\hline & $17 / \mathrm{F}$ & Seizures & NS & Normal & - & 一 \\
\hline Present case & $24 / \mathrm{M}$ & Seizures & Calcification & Normal & Calcification & * \\
\hline
\end{tabular}

$\mathrm{ND}=$ not done

Angio $=$ Angiography
NS $=$ not stated

$\mathrm{CT}=$ Computed Tomography
$*$ see text

MRI = Magnetic Resonance Imaging 
until further cases are studied and the characteristic image defined.

\section{REFERENCES}

1. Worster-Drought CV, Dickson W, McMeneny W. Multiple Meningeal and perineural tumors with analogous changes in the glia and ependyma (neurofibromatosis): with report of two cases. Brain 1937; 60: 85-117.

2. Rubinstein JL. Tumors of the central nervous system. In: 2nd series, Fascicule 6. Atlas of Tumor Pathology. Washington DC: Armed Forces Institute of Pathology 1972; 252-400.
3. Kasantikul V, Brown WJ. Meningio-angiomatosis in the absence of Von Recklinghausen's disease. Surg Neurol 1981; 15: 71-75.

4. Halper J, Scheithauer B, Okazaki H, et al. Meningio-angiomatosis: a report of six cases with special reference to the occurrence of neurofibrillary tagles. J Neuropathol Exp Neurol 1986;45:426-446.

5. Hozay J. Une angioneuromatose méningoencéphalique diffuse. Rev Neurol 1953; 89: 222-236.

6. Zimmerman R, Fleming C, Saint-Louis L, et al, Magnetic Resonance Imaging of Meningiomas. AJNR 1985; 6: 149-157. 